\title{
A Study on the Causative Factors of ESP Reading Intake
}

\author{
Yi Xie \\ Yantai Nanshan University \\ Yantai, China
}

\begin{abstract}
Input, intake and output are the most fundamental links in second language acquisition. With the development of cognitive science and the profound investigation of psycholinguistics and applied linguistics in the past decades, intake has been the research focus for many linguistic scholars. As where there is no input, there will be no intake. When there is no intake, there is no output. Reading, an important way of visual input and a main means of receiving information and language knowledge, is the crucial activity in and out of classroom. Therefore, this thesis aims to integrate the inputintake and ESP reading comprehension from a new perspective, discussing the causative elements that affect the transition from input to intake in the reading process. In addition, it is a significant subject to improve the quantity of intake and optimize the quality of intake for the great progress of foreign language teaching so as to facilitate comprehensible input and intake to the greater extent.
\end{abstract}

Keywords-comprehensible input; intake; second language acquisition; ESP

\section{INTRODUCTION}

Second language acquisition (SLA), as a subject, rose in the 1950s. As an independent discipline, second language acquisition established its theoretical system in the late 1960s and the early 1970s. There appeared various theories and hypotheses of how language input influenced second language acquisition. In the late 1970s and early 1980s, Krashen put forward a series of theories concerning second language acquisition, which are also the most influential and controversial theories in SLA. Of these hypotheses, the input hypothesis is the most important because it touches the essence of how the learners acquire their second language.

With the development of cognitive science and the profound investigation of psycholinguistics and applied linguistics in the past decade, intake has been the research focus for many linguistic scholars. Second language acquisition is studied in a broader framework of how people store and acquire knowledge in general. Though the relevant theories have made great contributions to SLA, there is still much room for further exploration.

The primary goal of the present research is to investigate the causative factors that affect the conversion from input to intake in ESP reading, combining the research results of language input-intake with ESP reading comprehension in foreign language classroom, which aims at optimizing their transition between input and intake in the reading process and improving reading efficiency.

\section{RESEARCH QUESTIONS AND OBJECTIVES}

The target language input is the language that learners are exposed to and it plays an essential role in the process of foreign language teaching and learning. This thesis aims to explore the following research questions.

Question 1: What is the relationship between input and intake?

Question 2: What are the primary factors that impede the transition from input to intake?

\section{RELATED RESEARCH ON THE RELATIONSHIP BETWEEN INPUT TO INTAKE}

Modern language learning theories posit that, the process of language learning is like this: input (reading, audio-lingual) -intake (processing, memory)-output (speaking, writing, translating) [1].

Krashen believes that the psychological process of language acquisition and language learning is: input-filterintake-organize-monitor-output.

Intake processes are cognitive mechanisms that mediate between input data and intake factors. They consist of psychological process that are specific to second language learning as well as those that are asked for general activities. As procedures and processes that are internal to the acquirer, intake processes remain the most important link in the input-intake--output chain. The intake processes that appear to form L2 development may be constituted under three broad categories: inferring, structuring, and restructuring. These operations seem to govern what appears in the acquirers' mind when they make an attempt to assimilate the target language system, that is, infer the linguistic system of the target language from the available and accessible input data, structure appropriate mental representations of the target language system, and restructure the developing system in light of further exposure and experience [2].

\section{A. The Quantity Relationship between Input and Intake}

Kumaravadivelu think that intake is the subset of input, while output is the subset of intake in terms of quantity, 
because the acquirers have processed the input partly or totally and integrated them into their interlanguage system[2].

Krashen's affective filter hypothesis holds that there is a filter process between input and intake because the affective factors, such as anxiety and lack of confidence. Furthermore, the input may be beyond the level of $i+1$, that is more difficult than comprehensible input (i+1), thus intake is less than input.

\section{B. The Quality Relationship between Input and Intake}

Carroll regards intake as a product. She depicts comprehended speech as a "speech signal which has been successfully parsed and re-encoded in semantic terms". Carroll rejects the view that intake consists of comprehended speech because it means that all learning will be related with concept learning. To her, comprehending speech is something that happens as a series of a successful parse of the speech symbols. She views intake as a subset of the input; stimuli that are perceived by the acquirer. She defines it as "that which is taken in by the hearer". In addition, perceived stimuli are understood as "transuded stimuli", or stimuli available for processors to extract further information from. Carroll persists that intake is not input to the internal mechanisms, but input to language parsers [2]

The process from input to intake in SLA is actually perceiving natural language information, searching for the relevance to the context according to the acquirer's existing knowledge, and working out the inference by the extralinguistic knowledge as well as decoding. The receiver not only comprehends the explicit meaning of the input from information conveyed by language symbols, such as words, phrases, sentences and paragraphs, etc, but also knows the implicit meaning of the input by combining existing experience with input information.

\section{The Main CAUSATIVE FACTORS THAT AFFECT ESP READING INTAKE}

The most important factors affecting ESP reading intake are vocabulary barriers, syntactic complexity and schema information or encyclopedic knowledge. Other factors include the quantity of input, attention or noticing in reading, affective factors etc. Now let's explore them one by one.

\section{A. Linguistic Knowledge}

Many experiments have shown that if the students encounter so many strange words or command very limited grammatical rules they have difficulty in getting the meaning from the words and the complex structure of the sentence. The linguistic knowledge consists of phonology, lexicology, semantics and syntax. They are the fundamental elements to acquire the foreign language.

In terms of contents of the reading intake instruction, teachers do not give a systematic and exhaustive direction on vocabulary learning, grammar rules, reading skills and social culture, which will prevent them from comprehending the reading passages. Therefore, lexicon and syntactic abilities should be improved at the first opportunity. In addition, the reading techniques, cultural background information are crucial elements in reading improvement especially for the intermediate and advanced learners.

ESP reading intake contains that of words, sentences and discourses. We depend upon morphological structure when meeting unfamiliar words. In accordance with the spreading activation model, sequences of words with analogous meanings are retrieved presciently. In the aspect of sentence comprehension, semantics rather than syntactic rules plays a more dominant role.

\section{B. Encyclopedic Knowledge}

Psycholinguistic research on comprehension has showed that the presence or absence of background information knowledge can dramatically influence the way we understand a piece of discourse. This indicates that top-down information, which provides general background knowledge about a text, is useful in the reading intake of larger language input because it helps activate mental association which then is helpful to overall intake This shows that if the reader possesses the background information, he will have a much better reading intake ability.

Schema theory illustrates a corresponding relationship between the information receiver and the reading materials. The reader brings to the language input materials the appropriate schemata. Schemata is formed through the readers' experiences with objects, people and social events, etc. Hence, the teachers should provide a series of text types to the students, to provide a comprehensive understanding and to enlarge their prior knowledge. That is to say, the reader's prior or background knowledge affects the understanding of the input materials. The ESP reading intake occurs when the reader applies his background knowledge to anticipate or expect the print content. The print refines and expands his background information in the course of reading.

\section{Motivation and Attitudes}

As the famous scientist Einstein says, "Interest is the best teacher." Interest determines the motivation of the acquirers. Motivation is a stimulator of learning and also a perception of the learning effectiveness. Motivations can be divided into the integrative motivation and the instrumental motivation.

Attitudes and motivations are closely related. Generally speaking, attitudes decide and affect motivation. Sometimes the special motivation may influence attitudes. Although most students are not aware that reading is on the first position in the syllabus and they even do not understand why reading competence is in the first place instead of the other four abilities. It is hard to say that most students form a proper attitude towards reading. Meanwhile, in China few students possess integrated motivation for English learning, most students learn English due to the instrumental motivation.

\section{Learning Strategies}

Oxford defines learning strategies as: specific actions taken by the learner to make learning easier, faster, more enjoyable, more self-directed, more effective, and more transferable to new situations. In the meanwhile, Oxford summarizes six learning strategies: taking risks wisely; remembering new 
language information according to its sound; finding out about language learning; cooperating with peers; switching to the mother tongue; repeating [3]152.

\section{PEDAGOGICAL IMPLICATIONS ON THE TEACHING OF ESP READING}

ESP reading comprehension is a significant learning task of learning and teaching in China. The students' efforts and the learning environment are critical. On the other hand, they need the teacher's correct guidance on reading studies. They cannot achieve success in reading without the teacher's proper guidance. As a teacher of reading courses, he teaches the students linguistic knowledge and reading skills. He also guides them to reach the aim in accordance with a wellplanned schedule, helps them grasp correct learning methods, encourages them to develop their potentialities and aptitude, cultivates their interest towards reading and helps them fulfill reading courses smoothly. Meanwhile, the teacher need be alert to improve his reading instruction methods occasionally.

At the first presentation stage, the teacher's main task is to serve as an informant: he knows the language and presents the material in such a way that the new language and the content as clear, interesting memorable as meaning of the possible. Since comprehensible, interesting and adequate input is causative factor for SLA, the presentation stage is the crucial stage for the whole class. Teachers must also make sure that students understand the purpose of the tasks and make full use of them. So the teacher is like a skillful conductor who encourages students to think over and do the comprehension exercises.

Undoubtedly, EFL teacher is very important not only for presenting English knowledge and organizing class activities, but also for facilitating acquisition process and eliciting learner's output. Teacher's questions will encourage students to use the target language and to create cooperative atmosphere. Furthermore, by analyzing the learners' responses, teachers will know how well the knowledge has been mastered. Most important of all, teachers provide students with opportunities to practice what they have learned and enhance their communicative competence.

The findings of the present study have both theoretical and pedagogical implications. First, they have confirmed the influence of cognitive style on reading, which shows that individual differences in cognitive style have certain effects on the reading process, reading style and reading ability. Second, based on the input hypothesis, the new intake research results are beneficial for English teachers to improve their teaching methods and instruct reading activities in order to cause students' reading abilities to become better. Finally, the new proposed cognitive models challenge present college English reading teaching. Teachers should highlight the individual differences, keep to the rules of language acquisition and design new cognitive models of reading based on the cognitive characteristics of students majoring in different disciplines [4].

\section{CONCLUSION}

This thesis explains the causative factors affecting ESP reading intake. Generally speaking, optimizing input is a premise, information processing is the core, and improving output is the object that consolidates language learning efficiency. The psychological processes in second language learning start from input. The more the acquirer pays attention to the input, the more language input can become intake. After intake, language material will undergo complex processes of interaction. This is very meaningful because the mechanism can guide us to efficient second language acquisition and overcome limitation of interlanguage, thus arriving at a high level of second language. In these interactive processes, due to such factors as mother tongue interference, interlanguage is created which is a kind of production [5]. The ultimate goal of second language acquisition is to acquire a high level of the target language. It is very important to design teaching activities to direct students to overcome limitations of interlanguage as early as possible. It just suits the comprehensible input hypothesis.

To optimize the ESP reading intake, the acquirers are the prerequisites of optimal intake. They should possess the aptitude, motivation, positive attitudes towards learning and efficient learning strategies, overcoming affective filter factors, such as the anxiety and lack of confidence. The role of teacher, who is responsible for input, is not neglectable. The teaching style, methods and their encouragement will give positive effects to the learners. The teachers should treat the students cordially, help overcome psychological barriers, form a good habit of learning, create a good condition for intake, and eventually cultivate the language competence.

In sum, intake is the essential link in the process of second language acquisition, the bridge between input and output. No input, no intake, and no intake, no output. Practically speaking, it is an important subject to enhance the quantity of intake in order to optimize the quality of intake for the foreign language teaching in China.

\section{REFERENCES}

[1] You Qida. Promote Input and Output, Improve English Competence [J] Foreign Language World, 2001 (6): 40-43

[2] KUMARAVADIVELU B. Understanding Language Teaching: From Method to Post-Method [M]. Mahwah, NJ, USA: Lawrence Erlbaum Associates, Incorporated, 2005: 25-54

[3] KEITH J. An Introduction to Foreign Language Learning and Teaching. [M]. Beijing: Foreign Language Teaching and Research Press, 2002: 94-152

[4] Sun Guangzhi. Individual Difference Factors and Second Language Acquisition Research [J]. Journal of Heilongjiang College of Education, 2004 (3) : 47-49

[5] $\mathrm{Hu}$ Rong. Interlanguage and Foreign Language Teaching [J]. Foreign Language Education, 1998 (3) : 21-25 